\title{
Influence of climatic conditions on productivity and adaptability of Camelina sativa
}

\author{
E L Turina ${ }^{1, *}$, and $T Y a$ Prakhova $^{2}$ \\ ${ }^{1}$ Research Institute of Agriculture of Crimea, 150 Kievskaya str., Simferopol, Republic of Crimea, \\ 295453, Russia \\ ${ }^{2}$ Federal Research Center for Bast Fiber Crops, st. Michurina, 1b, Lunino, Penza region, 442731, \\ Russia
}

\begin{abstract}
The purpose of the research is to assess the productivity and adaptability of Camelina sativa depending on the natural and climatic conditions of the forest-steppe zone of the Middle Volga region and the steppe Crimea. The researches were conducted in two regions (Penza and Crimea) with contrasting hydrothermal conditions in 2015-2019 years. Climate conditions in the years of researches were characterized by significant variability in both the degree of humidity and temperature regime in both regions. The hydrothermal coefficient in the Crimea varied in the range of $0.23-1.11$, in the conditions of Penza - from 0.45 to 1.10. The index of environmental conditions varied from -0.58 to 1.28 units depending on the natural and climatic zone. On average, in 2015-2019, the productivity of Camelina changed from 1.45 to $1.79 \mathrm{t} / \mathrm{ha}$ in Penza and from 0.56 to $1.66 \mathrm{t} / \mathrm{ha}$ in Crimea. The highest yield of Camelina sativa was recorded in 2016 in Penza and in 2017 in the Crimea and amounted to 1.79 and $1.66 \mathrm{t} / \mathrm{ha}$, respectively. The value of the index of environmental conditions is 1.17 and 1.28 with hydrothermal coefficient of 0.82 and 0.61 , respectively. Depending on the conditions of the year and the region, the oil content varied from 33.9 to $43.9 \%$. At the same time, there is a tendency to decrease the amount of oil for all years of study in the direction from the Crimea to the zone of the Penza region. Camelina sativa is characterized by a high level of resistance to stressful conditions $(0.49$ $1.10)$, differs in environmental adaptability (bi $=1.15-1.17)$, has a high fitness criterion, $41.2-41.5 \mathrm{~g} / \mathrm{m} 2$, depending on the region.
\end{abstract}

\section{Introduction}

The main factor in realizing the bioclimatic potential of each region, especially those located in unfavorable soil and climate conditions, is the cultivation of such crops that are most adapted to local, including unfavorable and extreme environmental conditions and differentially use unevenly distributed in time and space climate factors that limit the size and quality of the crop [1].

\footnotetext{
*Corresponding author: turina_e@ @niishk.ru
} 
At present, due to global transformations of climatic conditions that tend to increase temperatures, the issue of expanding the range of oilseeds and spreading the most adaptive crops that can form stable yields when changing thermal and water regimes is raised [2-4].

Due to its plasticity and tolerance to the conditions of cultivation, such crops include Camelina sativa, which has recently become increasingly popular in many regions, both in the Russian Federation and abroad, as a promising oilseed crop for the use of oilseeds for food, technical purposes and for the production of biodiesel [5-9].

Camelina is characterized by good adaptability to various climatic conditions, both favorable and stressful, cold resistance, high growth rates at low temperatures, early maturation, and the ability to tolerate soil and air drought [6-11].

The main economic value of Camelina sativa is its ability to form a high potential productivity in a wide range of soil and climatic conditions $[2,4,10]$.

In turn, its yield acts as an integral indicator and reflects the whole complex of biological properties and adaptive capabilities of the crop under specific agro ecological conditions [1].

For successful cultivation of crops in various climatic regions, the most important requirement for it is stability and adaptability to environmental factors. And in areas with a sharp manifestation of contrasting elements of the climate, this problem is especially relevant.

In this regard, the purpose of our researches was to assess the productivity and adaptability of Camelina sativa depending on the natural and climatic conditions of the forest-steppe zone of the Middle Volga region and the steppe Crimea.

\section{Research methods and conditions}

The researches were conducted in two regions (Penza and Crimea) with contrasting hydrothermal conditions in 2015-2019 years.

The climate of the forest-steppe of the Middle Volga region, which includes the Penza region, is moderately continental. The amount of annual precipitation varies in a wide range from 350 to $750 \mathrm{~mm}$. The average annual temperature is $5.3^{\circ} \mathrm{C}$. The sum of the effective temperatures during the growing season of crops is an average of $2450^{\circ} \mathrm{C}$.

Crimea is one of the sunniest regions, and the natural conditions of the Peninsula are particularly favorable for the cultivation of most agricultural crops. The climate of the steppe Crimea is continental. The average annual temperature here is $10.2^{\circ} \mathrm{C}$, with $350-450$ $\mathrm{mm}$ of precipitation per year. The sum of effective temperatures varies from 3300 to $3600^{\circ} \mathrm{C}$.

The yield of Camelina sativa was evaluated according to the existing guidelines for oilseeds [11].

The index of environmental conditions was determined by the method of S. A. Eberhart and W. A. Russel, the effect of interaction of environmental conditions and genotype was evaluated by the method of G. C. Tai, as described by V. A. Zykin and others [12].

Parameters of the overall adaptive capacity (bi) and yield variability were determined by the method of A.V. Kilchevsky and L. V. Khotyleva using dispersion and regression analyses [13].

The ecological stability of varieties was determined by the method of A. A. Rossielle and J. Hamblin (using the Ymax-Ymin equation) [14]. 


\section{Research results}

Climate conditions in the years of researches were characterized by significant variability in both the degree of humidity and temperature regime in both regions.

The index of environmental conditions varied quite widely from -0.58 to 1.28 units depending on the natural and climatic zone.

The most favorable conditions for the development of Camelina sativa were formed in 2015 and 2017 in the Penza region and in 2015 in the Crimea, the hydrothermal coefficient here was $1.02 ; 1.10$ and 1.11 , respectively (table 1 ).

Table 1. Hydrothermal conditions for the development of Camelina sativa by regions.

\begin{tabular}{|c|c|c|c|c|c|}
\hline Region & Years & $\begin{array}{c}\text { Daily temperature, } \\
{ }^{\circ} \mathrm{C}\end{array}$ & $\begin{array}{c}\text { Amount of } \\
\text { precipitation, } \\
\mathrm{mm}\end{array}$ & HTC & $\begin{array}{c}\text { Index of } \\
\text { environmental } \\
\text { conditions, Ij }\end{array}$ \\
\hline \multirow{5}{*}{ Penza } & 2015 & 5.1 & 178.1 & 1.02 & 0.98 \\
\hline & 2016 & 5.3 & 155.8 & 0.82 & 1.17 \\
\hline & 2017 & 5.0 & 128.8 & 1.10 & 1.03 \\
\hline & 2018 & 5.0 & 50.7 & 0.45 & -0.58 \\
\hline & 2019 & 5.3 & 98.1 & 0.63 & -0.62 \\
\hline \multicolumn{2}{|c|}{ Average experience } & 5.1 & 122.3 & 0.80 & - \\
\hline \multirow{5}{*}{ Crimea } & 2015 & 9.7 & 314.1 & 1.11 & 0.98 \\
\hline & 2016 & 11.3 & 287.4 & 0.82 & 0.84 \\
\hline & 2017 & 8.9 & 139.9 & 0.61 & 1.28 \\
\hline & 2018 & 10.3 & 90.2 & 0.23 & -0.74 \\
\hline & 2019 & 8.4 & 133.9 & 0.60 & 0.97 \\
\hline \multicolumn{2}{|c|}{ Average experience } & 9.7 & 193.1 & 0.67 & - \\
\hline
\end{tabular}

In the Crimea, during the growing season of Camelina sativa in 2014-2015, $314.1 \mathrm{~mm}$ of precipitation fell, almost an annual norm. Only in the third decade of September, 100.2 $\mathrm{mm}$ of precipitation fell, which is more than the 3-month norm. Abnormal precipitation also fell in the second half of the third decade of May 2015. Their amount was $155 \mathrm{~mm}$ ( $816 \%$ of the decadal norm). Temperature indicators during the vegetation period were close to the average annual temperature. The HTC was 1.11 units.

The vegetation conditions of 2016 in the Crimea were characterized as moderately dry, with the HTC of 0.82 . There is a shortage of precipitation at elevated temperatures in the autumn period. The spring-summer development of the Camelina sativa was held in favorable conditions. May and June 2016 were the leaders in the amount of precipitation compared to the average annual data.

Conditions in 2017 and 2019 were characterized as dry, with a hydrothermal coefficient of 0.61 and 0.60 , respectively. The amount of precipitation was 139.9 and $133.9 \mathrm{~mm}$, with average daily temperatures of 8.9 and $8.4^{\circ} \mathrm{C}$. Despite the fact that there was not enough precipitation in the spring of 2017, Camelina sativa plants formed a fairly high yield due to the reserves of productive moisture in the soil. The index of the environment conditions for the development of Camelina sativa here reached the highest values and amounted to 1.28.

The most severe weather conditions were in 2018 (HTC -0.23). The amount of precipitation during the growing season was $90.2 \mathrm{~mm}$ against the background of high temperature conditions. The overall index of environmental conditions here was -0.74 . These conditions led to a significant inhibition of the growth and development of Camelina sativa, which led to a significant decrease in the yield of Camelina sativa.

In the conditions of the Penza region, the most optimal for water availability were 2015 and 2017, the HTC reached the optimal value and was 1.02 and 1.10. At the same time, the best conditions for the formation of yield were in 2017, the index of environmental conditions was 1.03. 
The most stressful conditions for the growth and development of Camelina sativa were formed in 2018 and 2019, and were characterized as acutely arid, the HTC was $0.45-0.63$.

The growing season of Camelina sativa in 2016 took place in insufficiently humid conditions with a HTC of 0.82 units and an average daily temperature of $5.3^{\circ} \mathrm{C}$. However, the value of the index of environmental conditions is high and is 1.17 .

Based on the prevailing environmental conditions caused by the hydrothermal regime, the yield of Camelina sativa varied widely. On average, in 2015-2019, the productivity of Camelina sativa ranged from 1.45 to $1.79 \mathrm{t} / \mathrm{ha}$ in Penza and from 0.56 to $1.66 \mathrm{t} / \mathrm{ha}$ in Crimea (table 2).

Table 2. Productivity of Camelina sativa by regions.

\begin{tabular}{|c|c|c|c|c|}
\hline \multirow{2}{*}{ Years } & \multicolumn{2}{|c|}{ Penza } & \multicolumn{2}{c|}{ Crimea } \\
\cline { 2 - 5 } & $\begin{array}{c}\text { Yield, } \\
\text { t/ha }\end{array}$ & $\begin{array}{c}\text { Oil content, } \\
\%\end{array}$ & $\begin{array}{c}\text { Yield, } \\
\text { t/ha }\end{array}$ & $\begin{array}{c}\text { Oil content, } \\
\%\end{array}$ \\
\hline 2015 & 1.69 & 40.4 & 1.46 & 40.8 \\
\hline 2016 & 1.79 & 38.9 & 1.49 & 43.9 \\
\hline 2017 & 1.65 & 39.6 & 1.66 & 41.3 \\
\hline 2018 & 1.51 & 40.2 & 0.56 & 33.9 \\
\hline 2019 & 1.45 & 39.1 & 1.50 & 39.5 \\
\hline Average & 1.62 & 39.6 & 1.33 & 39.9 \\
\hline $\begin{array}{c}\text { smallest } \\
\text { significant } \\
\text { difference } 05\end{array}$ & 0.14 & 1.02 & 0.09 & 1.17 \\
\hline
\end{tabular}

The highest yield of Camelina sativa was recorded in 2016 in Penza and in 2017 in the Crimea and amounted to 1.79 and $1.66 \mathrm{t} / \mathrm{ha}$, respectively. The value of the index of environmental conditions here is 1.17 and 1.28 , while the integral moisture index, reflecting the ratio of temperature and precipitation, was only 0.82 and 0.61 , respectively. The positive value of the index of environmental conditions is formed due to a more complete realization of the potential of the culture genotype in these conditions.

In the Crimea, very low productivity of Camelina sativa $(0.56 \mathrm{t} / \mathrm{ha})$ was noted in 2018. Here the complex influence of water and temperature factors has affected, the index of environmental conditions here has a negative value and is -0.74 , which is a consequence of low adaptive potential.

Camelina sativa differed not only in the level of manifestation of a sign of productivity, but also in the manifestation of the quality of oilseeds. Depending on the conditions of the year and the region, the oil content varied from 33.9 to $43.9 \%$. At the same time, there is a tendency to decrease the amount of oil for all years of study in the direction from the Crimea to the zone of the Penza region, which is due to a more severe temperature regime, with the exception of 2018 .

The assessment of the interaction "genotype-environment" with the help of dispersion analysis showed a high degree of influence of the climate factor on the variability of productivity of Camelina sativa in the "region-years" system.

The studied factors significantly affected the productivity of Camelina sativa varieties $(\mathrm{Fa}>\mathrm{Ft}$ ) regardless of the natural and climatic region (table 3$)$. 
Table 3. Dispersion analysis of productivity of Camelina sativa.

\begin{tabular}{|c|c|c|c|c|c|}
\hline \multirow[b]{2}{*}{ Source of variation } & \multicolumn{2}{|c|}{ Criterion F } & \multirow{2}{*}{$\begin{array}{l}\text { Share of } \\
\text { factor } \\
\text { influence }\end{array}$} & \multirow{2}{*}{$\begin{array}{c}\text { smallest } \\
\text { significa } \\
n t \\
\text { differenc } \\
\mathrm{e}_{05}\end{array}$} & \multirow[b]{2}{*}{$\begin{array}{c}\text { Interaction } \\
\text { effect }\end{array}$} \\
\hline & actual & theoretical & & & \\
\hline Factor A (region) & 4.52 & 3.94 & 32.3 & 0.18 & 0.21 \\
\hline Factor B (years) & 5.96 & 3.32 & 34.3 & 0.15 & 0.15 \\
\hline Interaction $\mathrm{AB}$ & 4.85 & 3.09 & 27.7 & 0.11 & 0.16 \\
\hline Random factors & - & - & 5.7 & - & - \\
\hline
\end{tabular}

The calculation of the contribution of factors showed that the leading factor is "years", the value of which was $34.3 \%$, the value of the factor "region" was $32.3 \%$. Share of the influence of the interaction of factors years and region is $27.7 \%$, which increases the adaptability of the genotype and reduces the influence of the environment.

The yield variability of Camelina sativa grown in the Penza region is weak and amounts to $11.6 \%$. Coefficient of crop variation in the Crimea reaches an average value of $21.9 \%$, which shows a relatively high genetic protection against the action of limiting factors (table 4).

Table 4. Adaptability parameters of Camelina sativa.

\begin{tabular}{|c|c|c|}
\hline Indicator & Penza & Crimea \\
\hline The variability of yield, \% & 11.6 & 21.9 \\
\hline The stability index, \% & 16.10 & 15.92 \\
\hline Environmental adaptability bi & 1.17 & 1.15 \\
\hline Environmental sustainability & 0.49 & 1.10 \\
\hline The General criterion of fitness, $\mathrm{g} / \mathrm{m}^{2}$ & 41.5 & 41.2 \\
\hline
\end{tabular}

At the same time, in both regions, Camelina sativa had a high stability index for this crop of $15.92-16.10 \%$.

After all, both in optimal growing conditions and in extreme conditions, the Camelina sativa shows tolerance to all stressors and maximum adaptability to specific environmental conditions.

Despite fluctuations in yield depending on the changing hydrothermal factor, Camelina sativa shows stability and plasticity, regardless of the region, the environmental adaptability of which is 1.15 and 1.17 . This shows a weak reaction of the culture to the varying degree of manifestation of limiting factors (temperature or moisture).

The parameters of stability and environmental sustainability have shown that Camelina sativa shows a wide range of its adaptability to stressful growing conditions, both in the conditions of Penza and in the Crimea. The general criterion of fitness of the Camelina sativa had high positive values of $41.2-41.5 \mathrm{~g} / \mathrm{m} 2$, depending on the region.

\section{Conclusion}

Thus, the environmental sustainability of the crop, its adaptability and tolerance to environmental factors will ensure a sufficiently high yield in favorable conditions of cultivation and stability in stressful conditions in different localities and in different years.

Camelina sativa is characterized by a high level of resistance to stress conditions (0.491.10), is characterized by environmental adaptability ( $\mathrm{bi}=1.15-1.17)$, has a high fitness criterion, which contributes to the formation of a high and stable yield of oilseeds (1.33$1.62 \mathrm{t} / \mathrm{ha}$ ) in various contrasting growing conditions. 


\section{References}

1. Zhuchenko A A 2001 Adaptive system of plant breeding (ecological and genetic basis) (Moscow: Friendship university of Russia publishing house)

2. Turina E L, Prakhova T Y, Prakhov V A 2019 Assessment of productivity and adaptability of Camelina Sativa varieties IOP Conf. Series: Earth and environmental science (Electronic materials vol 341) Kurgan state agricultural academy named after T.S. Maltsev (Bristol: IOP Publishing Ltd) pp 012-085 doi:10.1088/1755$1315 / 341 / 1 / 012085$

3. Prakhov V A 2017 Crop properties of Camelina sativa depending on fertilizers Collection of materials of the conference Topical issues of fertilizer application in agriculture (Vladikavkaz: Agroizdat) pp 104-106

4. Tomasi P, Dyer J M, Jenks M A, Abdel-Haleem H 2018 Characterization of leaf cuticular wax classes and constituents in a spring Camelina sativa diversity panel Industrial crops and products 112 247-251 doi: 10.1016/j.indcrop.2017.11.054

5. Bekuzarova S A, Dulaev T A 2016 Camelina sativa - a new culture in North OssetiaAlania New non-traditional plants and prospects for their use 12 182-184

6. Czarnik M, Jarecki W, Bobrecka-Jamro D 2018 Reaction of winter varieties of false flax (Camelina sativa (L.) Crantz) to the varied sowing time Journal of central European agriculture 19(3) 571-586 doi: /10.5513/JCEA01/19.3.2054

7. Hoseini S S, Najafi G, Ghobadian B, Ebadi M T, Mamat R, Yusaf T 2020 Biodiesels from three feedstock: The effect of graphene oxide (GO) nanoparticles diesel engine parameters fuelled with biodiesel Renewable energy 145 190-201 doi: 10.1016/j.renene.2019.06.020

8. Prakhova T Y 2020 Dynamics of oil and fatty acid accumulation in brassicaceae seeds Russian agricultural science 46 15-18 doi:10.3103/S1068367420010139

9. Ratusz K, Symoniuk E, Wroniak M, Rudzinska M 2006 Bioactive compounds, nutritional quality and oxidative stability of cold-pressed Camelina (Camelina sativa L.) Oils applied sciences-basel 8(12) 2606 doi: 10.3390/app8122606

10. Turina E L, Kulinich R A, Molyar S A 2016 Features of cultivation of Camelina sativa in the Crimea Tavricheskiy bulletin of agricultural science 4(8) 63-71

11. Prakhov V A 2015 Screening of source material for selection of Camelina sativa Collection of materials of the conference Scientific support for the development of the agro-industrial complex of Russia (Penza: Osnova) 72-77

12. Lucomec V M 2007 Methods of conducting field and agrotechnical experiments with oilseeds (Krasnodar: VNIIMK)

13. Zykin V A, Belan I A, Yusov V S, Nedorezkov V D, Ismagilov R R, Kadikov R K, Islamgulov D R 2015 Method of calculation and evaluation of parameters of ecological plasticity of agricultural plants (Ufa: Mir)

14. Kilchevsky A V, Khotyleva L V 2008 Genetic bases of plant breeding General plant genetics 1 50-56

15. Rossielle A A, Hamblin J 2001 Theoretical aspects of selection for yield in stress and no stress environments Crop Science 6 12-23 